\title{
APP DA LAGOA DOS PATOS, DIAGNÓSTICO PRELIMINAR DO ESTADO ATUAL DA OCUPAÇÃO, CLASSIFICAÇÃO DO USO DO SOLO E ANÁLISE ECONÔMICA DA PRODUÇÃO RURAL EXISTENTE
}

\author{
APP OF LAGOA DOS PATOS, PRELIMINARY DIAGNOSIS OF CURRENT \\ STATE OF OCCUPANCY CLASSIFICATION OF LAND USE AND ECONOMIC \\ ANALYSIS OF EXISTING RURAL PRODUCTION
}

\section{Resumo}

Leandro Marques Pitol ${ }^{1}$ Jairo Afonso Henkes ${ }^{2}$

Este trabalho apresenta um diagnóstico preliminar do estado atual do uso e ocupação do solo situado na área de preservação permanente de uma das maiores lagoas costeiras do mundo, a Lagoa dos Patos, situado na região litorânea do Rio Grande do Sul, através de técnicas de geoprocessamento utilizando-se de dados geoespaciais públicos disponíveis publicamente em sites de órgãos governamentais. $\mathrm{O}$ estudo comprovou que grande parte da APP da Lagoa encontra-se devidamente preservada e que o restante encontra-se irregular devido às atividades agrossilvipastoris já consolidadas há anos na região. Ao mesmo tempo se demonstra a importância econômica de tais atividades mediante análise de informações financeiras disponibilizadas por representantes setoriais e empresas locais.

Palavras-chave: Geoprocessamento, APP, Lagoa dos Patos.

\section{Abstract}

This work presents a preliminary diagnosis the current use and occupation of soil located in a permanent preservation area in one of the largest coastal lagoons in the world, the Lagoa dos Patos. It is located on the coast of the Rio Grande do Sul State. The results were obtained through geoprocessing techniques using geospatial data available in official web sites and databases. This study showed that most of the PPA of the lagoon is well preserved and the rest of the area was found to be legally irregular due to agro forest activities already consolidated in the region. At the same time the economic relevance of such activities is found in financial information analysis available in databases of local official representatives and private companies.

Keywords: GIS, PPA, Lagoa dos Patos.

\section{INTRODUÇÃO}

As APPs, áreas de preservação permanentes, são terras situadas em zonas urbanas ou rurais, cobertas ou não por vegetação nativa, que possuem a função de proteger principalmente os recursos hídricos, como rios, lagos e lagoas. Porém a sua importância não se estende apenas à proteção dos mananciais, mas também contribuem

\footnotetext{
${ }^{1}$ Graduando em Tecnologia em Gestão Ambiental pela Universidade do Sul de Santa Catarina UNISUL, e-mail: leandro.pitol@unisul.br

${ }^{2}$ Prof. MSc. pela Universidade do Sul de Santa Catarina - UNISUL, e-mail: Jairo.Henkes@unisul.br
} 
para a melhoria da biodiversidade, da conservação da fauna e flora e da cobertura vegetal dos terrenos, garantido assim à população melhor qualidade de vida com acesso ao meio ambiente saudável. As APPs devem ser mantidas preservadas quando ainda preservam sua cobertura vegetal original ou recuperadas por seus proprietários em caso de passivo ambiental existente. A supressão de vegetação situada em APP só é admitida em casos de utilidade pública ou interesse social, mediante estudo de avaliação dos impactos ambientais a serem ocasionados pela atividade e pela garantia de compensação ambiental pelos responsáveis da mesma. (BRASIL, 2013)

No Brasil grande parte dos Lagos e Lagoas estão situadas na planície litorânea que constitui as restingas e são representados por várias lagoas e lagunas dos mais variados tamanhos, desde muito pequenas até grandes lagoas costeiras como a Lagoa dos Patos.

A Lagoa dos Patos (com as seguintes coordenadas: Lat.: -31.162061º, Long.: $51.342468^{\circ}$ ), situada no sul do Estado do Rio Grande do Sul, possui cerca de $230 \mathrm{~km}$ de extensão chegando a atingir $60 \mathrm{~km}$ de largura em determinados pontos, perfazendo uma lâmina d'água com aproximadamente 936.874 hectares. É uma das maiores lagoas costeiras do mundo, possui profundidade média de 6 metros, sendo assim considerada como um corpo lagunar de águas rasas. Possui expressiva importância ambiental e econômica para o Estado, onde as atividades como, recreação e turismo, uso da água para abastecimento e irrigação, coletor de esgotos domésticos e industriais, pesca aquicultura, matéria prima para atividade industrial, etc., são diretamente beneficiadas por ela (TYRREL \& GEORGE, 2004). A Lagoa dos Patos é também utilizada como rota de navegação entre Porto Alegre e Rio Grande, mas, devido a sua profundidade, os navios de grande porte fazem o carregamento e o descarregamento em Rio Grande (PEREIRA et al, 2005).

\section{OBJETIVOS}

O presente trabalho tem por objetivo apresentar o diagnóstico preliminar do uso atual do solo situado em áreas de preservação permanente-APP da Lagoa dos Patos. Mensurar a área total de APP, a área correspondente a cada município limítrofe à Lagoa e classifica-las de acordo com as atividades existentes. Calcular o impacto da conversão, 
das áreas produtivas situadas em APP, para o ESTADO/UNIÃO e para os produtores rurais envolvidos, através da utilização de dados geoespaciais disponibilizados por entidades governamentais em seus respectivos sites.

\section{MATERIAIS E MÉTODOS}

O trabalho foi desenvolvido através de técnicas de geoprocessamento, pesquisa bibliográfica, análise da legislação específica, consulta a órgãos públicos governamentais, representantes setoriais, e utilização de informações geográficas sobre a cobertura vegetal e recursos hídricos da região.

\subsection{Ferramentas}

Para mensuração e classificação das áreas foi utilizado o software ARCVIEW, da fabricante ESRI, como ferramenta de geoprocessamento. Este software utiliza-se de um conjunto de técnicas de processamento de dados destinado a extrair informação

ambiental a partir de uma base de dados georreferenciada (Silva, 1999). É uma ferramenta de grande importância para o monitoramento da biodiversidade, devido à capacidade de coleta de dados para diversos estudos, bem como realizar análises complexas, ao integrar informações de diversas fontes de dados.

\subsection{Base de informações}

Como base de dados, utilizou-se arquivos no formato shapefiles, disponibilizados por órgãos governamentais como: Limites Municipais do RS, ofertado pelo Instituto Brasileiro de Geografia e Estatística - IBGE; Base Cartográfica Vetorial Contínua (Cartas do Exército) do Rio Grande do Sul, disponibilizada pela Universidade Federal do Rio Grande do Sul - UFRGS; Mapeamento da Cobertura Vegetal do Bioma Pampa, disponibilizado pelo Ministério do Meio Ambiente - MMA e dados secundários sobre atividades econômicas da região.

\subsection{Legislação aplicada}

O Brasil possui uma da mais sofisticadas legislações para proteção das áreas de 
preservação, em nível federal, estadual e até municipal. Este artigo baseia-se na Lei $\mathrm{N}^{\mathrm{o}}$ 12.651/2012, que institui o novo código florestal brasileiro, para correta mensuração e demarcação da área de preservação da lagoa em estudo, consonante o Capítulo II, Seção I, Artigo $4^{\circ}$, Inciso II, que considera como área de preservação em áreas rurais ou urbanas para efeito desta lei:

II - as áreas no entorno dos lagos e lagoas naturais, em faixa com largura mínima de:

a) 100 (cem) metros, em zonas rurais, exceto para o corpo d'água com até 20 (vinte) hectares de superfície, cuja faixa marginal será de 50 (cinquenta) metros;

b) 30 (trinta) metros, em zonas urbanas.

\subsection{Análise buffer}

O buffer é uma ferramenta de geoprocessamento que permite a criação automática de uma poligonal, com largura de offset definida pelo usuário, a partir de um perímetro externo de uma feição escolhida, neste caso a Lagoa em questão, a Figura 1 exemplifica a funcionalidade da ferramenta. (ESRI, 1999)

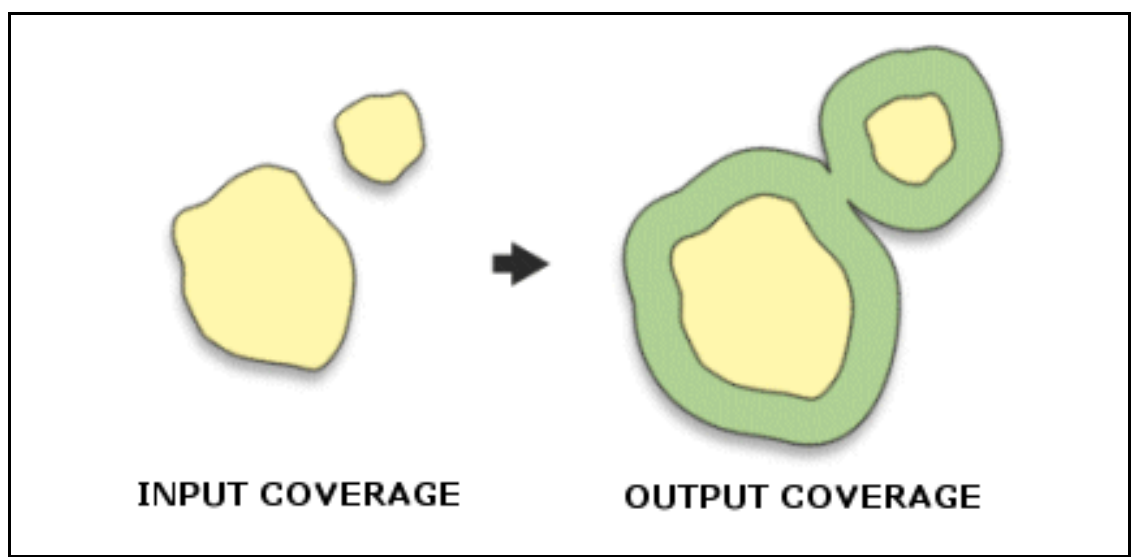

Figura 1 - Ilustração da função buffer. Fonte: ESRI

O perímetro da Lagoa dos Patos utilizado é oriundo da Base Cartográfica Vetorial Contínua, sendo desconsiderados os perímetros do Lago Guaíba e Lagoa do Casamento. Através da ferramenta buffer foi definida uma largura de 100 metros no entorno da Lagoa a fim de compor a área de preservação permanente da mesma nas zonas rurais e, 30 metros para as áreas urbanas, definidas com auxílio da base 
cartográfica supracitada.

\subsection{Análise intersect}

Esta análise permite reunir as informações entre dois arquivos shapefiles tendo como limite o espaço de intersecção entre os arquivos, ou seja, calcula uma interseção geométrica atributos de entrada. Atributos ou partes de atributos que se sobrepõem em todos os shapefiles serão preservados para o arquivo de saída. No presente trabalho esta ferramenta possibilitou o levantamento da área de preservação pertencente a cada município, tendo como base o arquivo com os Limites Municipais do IBGE. A Figura 2 ilustra a função da ferramenta. (ESRI, 1999)

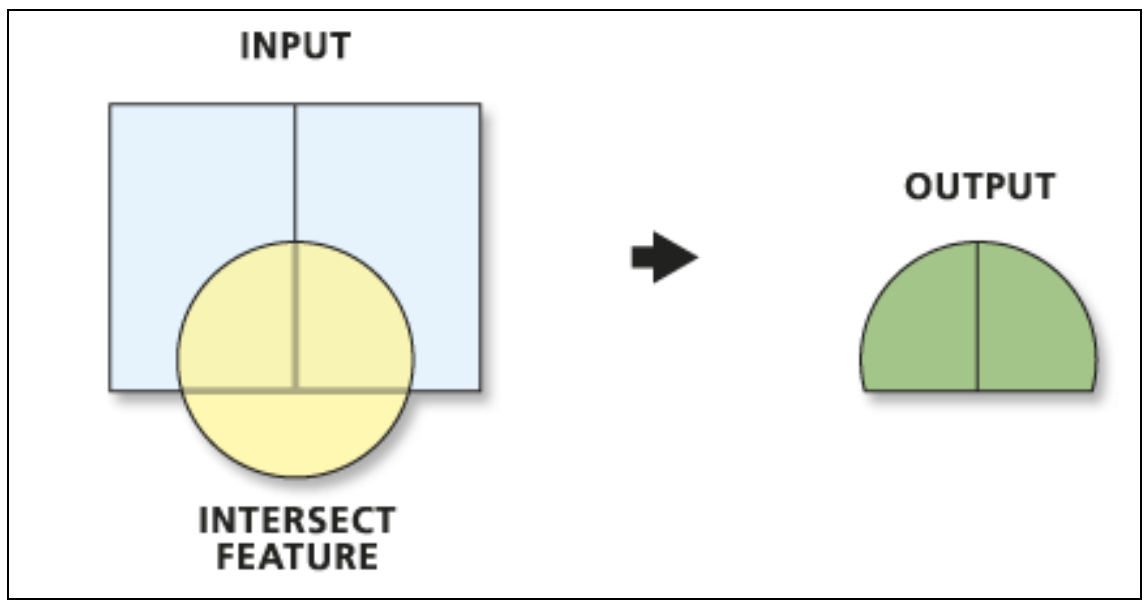

Figura 2 - Ilustração da função intersect. Fonte: ESRI

\subsection{Análise clip}

A ferramenta clip permitiu classificar o uso e ocupação do solo na APP da Lagoa dos Patos, através do recorte entre os arquivos shapefiles da poligonal da APP definida pela operação buffer e mapeamento da cobertura vegetal no bioma Pampa, MMA. E também definir a classificação do uso por município. Na Figura 3 está exemplificada a funcionalidade da ferramenta. (ESRI, 1999) 


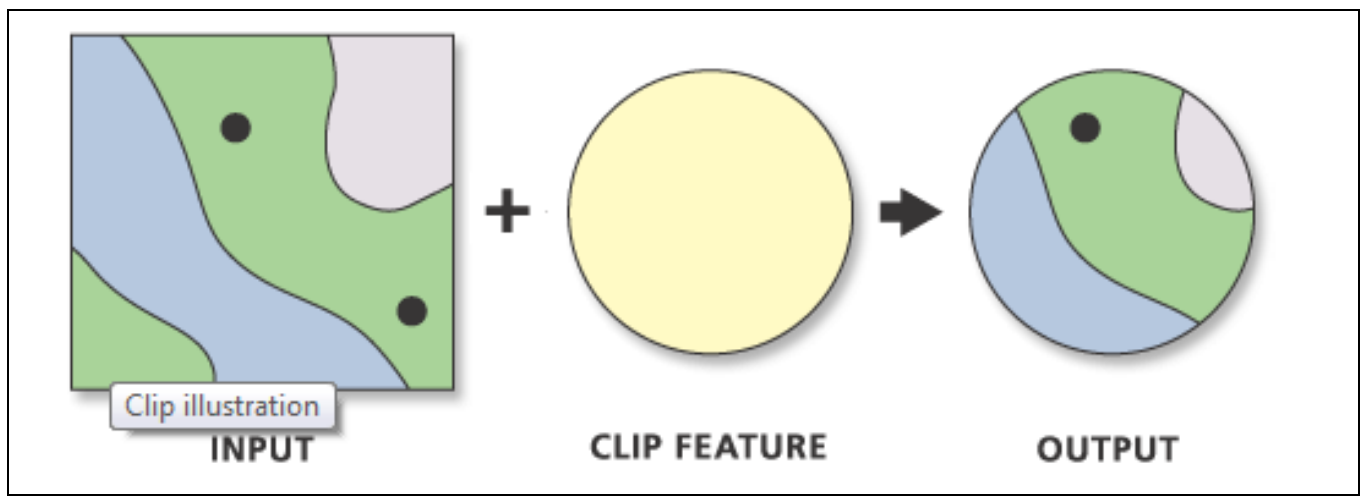

Figura 3 - Ilustração da função clip. Fonte: ESRI

\subsection{Análise econômica das áreas produtivas situadas na APP}

Esta análise tem como objetivo demonstrar a importância econômica das áreas produtivas, situadas na APP da Lagoa, através de pesquisa de mercado e produção, em sites específicos como o Instituto Rio-Grandense do Arroz (IRGA), Secretaria Estadual da Agricultura Pecuária e Agronegócio (SEAPA/RS), informações oriundas do Censo Agropecuário do Instituto Brasileiro de Geografia e Estatística (IBGE, 2006) e Anuário da Associação Brasileira de Empresas Florestais (ABRAF, 2012). Tal análise aponta os rendimentos das atividades por hectare, receita gerada e a respectiva tributação.

\section{RESULTADOS E DISCUSSÕES}

\subsection{Análise buffer}

A análise possibilitou a demarcação geográfica da APP da Lagoa dos Patos, conforme situação demonstrada na Figura 4 a seguir, sendo uma zona de abrangência de 100 metros, em projeção horizontal, a partir do perímetro externo da referida lagoa. A área total da APP encontrada nesta análise é de 8.660,88 hectares. 


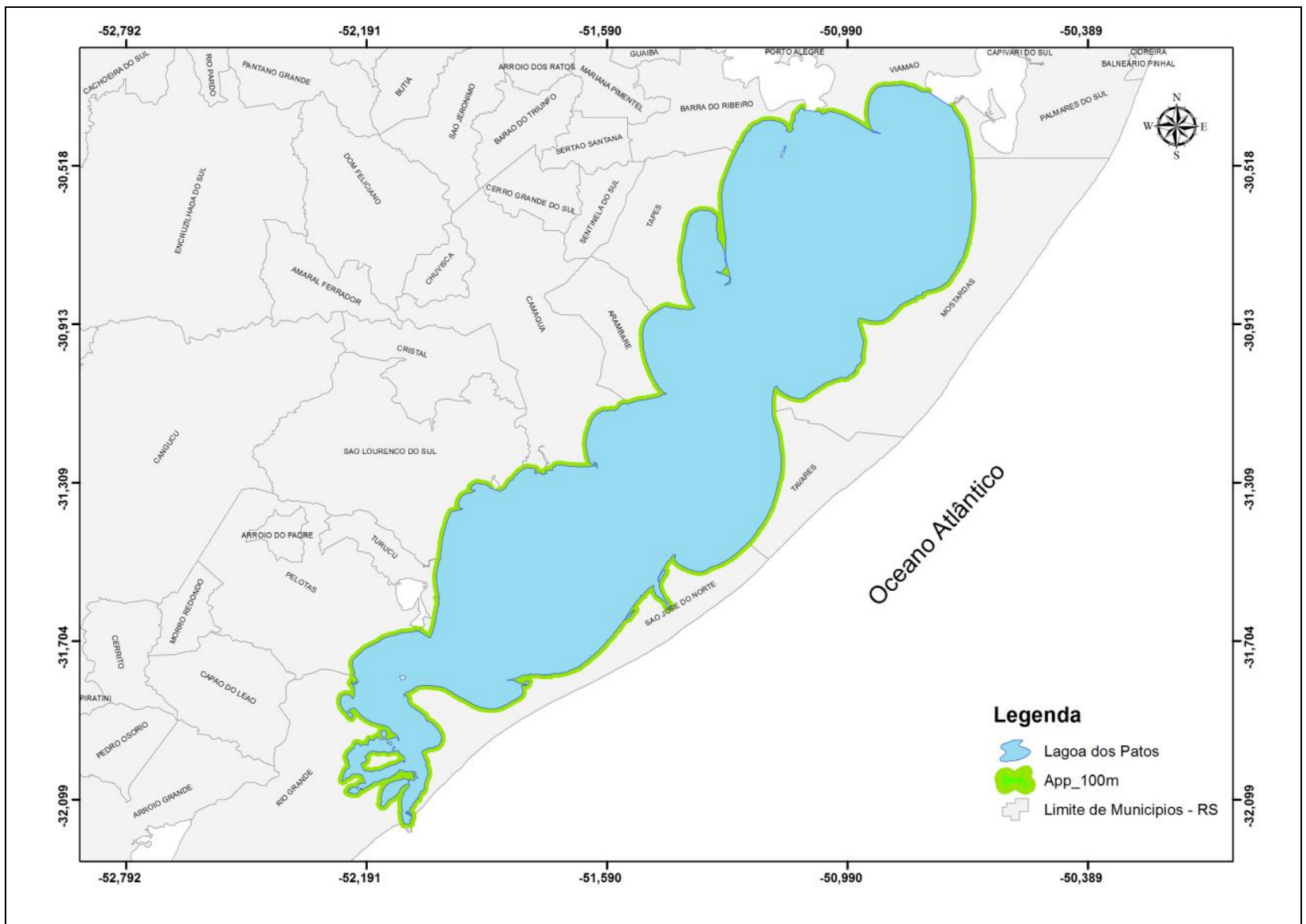

Figura 4 - Mapa da Lagoa dos Patos e App.

\subsection{Análise intersect}

A Tabela 1 é resultado da análise inttersect, onde a poligonal da APP foi dividida, conforme os limites municipais do RS, permitindo definir a quantidade de área de preservação permanente da Lagoa dos Patos que é de responsabilidade dos respectivos municípios.

Tabela 1 - Quadro de Áreas por Município.

\begin{tabular}{lrr|}
\hline \multicolumn{1}{c}{ Município } & \multicolumn{1}{c}{ Área (ha) } & \multicolumn{1}{c|}{$\%$} \\
\hline S.J. do Norte & 2017.13 & $23.29 \%$ \\
Rio Grande & 1571.34 & $18.14 \%$ \\
São Lourenço do Sul & 366.75 & $4.23 \%$ \\
Tapes & 1022.66 & $11.81 \%$ \\
Viamão & 445.34 & $5.14 \%$ \\
Pelotas & 212.79 & $2.46 \%$ \\
Turuçu & 263.01 & $3.04 \%$
\end{tabular}




$\begin{array}{lrr}\text { Camaquã } & 497.91 & 5.75 \% \\ \text { Arambaré } & 347.47 & 4.01 \% \\ \text { Barra do Ribeiro } & 289.52 & 3.34 \% \\ \text { Palmares do Sul } & 150.53 & 1.74 \% \\ \text { Mostardas } & 1092.30 & 12.61 \% \\ \text { Tavares } & 384.12 & 4.44 \% \\ \text { TOTAL } & \mathbf{8 6 6 0 . 8 8} & \mathbf{1 0 0 \%}\end{array}$

Fonte: Autor

\subsection{Resultados da análise clip}

Esta talvez seja a etapa mais importante do trabalho, através desta análise consegue-se diagnosticar exatamente o estado atual de uso e ocupação do solo, com foco na área de preservação permanente da Lagoa dos Patos, assim como sua classificação e divisão por municípios. Consonante a Tabela 2 , podemos verificar a situação geral da APP.

Tabela 2 - Classificação do Uso do Solo.

\begin{tabular}{|c|c|c|}
\hline Uso do Solo & $\begin{array}{l}\text { Área } \\
\text { (ha) }\end{array}$ & $\%$ \\
\hline Formação Pioneira com influencia pluvial $^{3}$ & $4.625,23$ & $53 \%$ \\
\hline Pecuária & 688,88 & $8 \%$ \\
\hline Dunas & 911,34 & $11 \%$ \\
\hline Área Urbana & 151,77 & $2 \%$ \\
\hline Silvicultura & 630,41 & $7 \%$ \\
\hline Água & 236,98 & $3 \%$ \\
\hline Estepe Gramíneo-Lenhosa & 42,36 & $0,5 \%$ \\
\hline Agricultura cultivos cíclicos ${ }^{4}$ & 925,03 & $11 \%$ \\
\hline Floresta Nativa & 448,88 & $5 \%$ \\
\hline TOTAL & $8.660,88$ & $100 \%$ \\
\hline
\end{tabular}

Fonte: Autor

\footnotetext{
${ }^{3}$ Vegetação de várzeas, que representa uma tipologia relacionada a ambientes naturais de grande fragilidade. (K0ZERA ET AL, 2009)

${ }^{4}$ Rizicultura - Cultivo de arroz
} 
O quadro de áreas demonstra que $74 \%$ da área de preservação permanente da Lagoa dos Patos encontram-se regular perante a legislação brasileira, perfazendo uma área total de 6.416,56 hectares. Em contrapartida a análise aponta uma área irregular com 2.244,32 hectares correspondendo a 26\% da APP. Para esta classificação, considera-se irregular as atividades de pecuária, silvicultura e agricultura de cultivos cíclicos (rizicultura da região).

O percentual de área regular, na APP da Lagoa dos Patos, se mostra otimista frente a outros levantamentos semelhantes, a exemplo, o estudo dos níveis de ocupação na Lagoa do Catú, em Aquiraz no Ceará, que apontou uma elevada pressão antrópica sob a APP da Lagoa, que praticamente não possui mais nenhuma fração de sua vegetação nativa conservada. (GONDIM et al., 2009). Outra situação semelhante é apresentada pelo levantamento do uso da terra situada na APP da Lagoa do Uruaú, em Beberibe no Ceará, que apresentou conflitos entre o uso e ocupação e a necessidade de proteção em 49\% da área de APP da Lagoa, constatando a necessidade de existência de um plano de monitoramento na região por parte dos órgãos governamentais. (MESQUITA et al, 2012). No trabalho realizado em Itapemirim no Espirito Santo, para fins de levantamento da vulnerabilidade da APP da Lagoa Guanandi, constatou-se que o estado da ocupação irregular que classifica a situação como de alta fragilidade ambiental com diversas áreas de extrema perturbação. (COUTINHO et al, 2011)

Através da interpretação dos dados obtidos através da análise clip, foi possível também descobrir o percentual das áreas regulares e irregulares, pertencentes a cada município limítrofe a lagoa em questão. Tabela 3.

Tabela 3 - Percentual das áreas regulares e irregulares por município

\begin{tabular}{|lcc|}
\hline \multicolumn{1}{c}{ Município } & \% Área Regular & $\begin{array}{c}\text { \% Área } \\
\text { Irregular }\end{array}$ \\
\hline Arambaré & $5 \%$ & $1 \%$ \\
Barra do Ribeiro & $4 \%$ & $3 \%$ \\
Camaquã & $7 \%$ & $1 \%$ \\
Mostardas & $7 \%$ & $29 \%$ \\
Palmares do Sul & $2 \%$ & $0 \%$ \\
Pelotas & $3 \%$ & $0 \%$ \\
Rio Grande & $20 \%$ & $13 \%$
\end{tabular}




\begin{tabular}{lcc} 
S.J. do Norte & $21 \%$ & $29 \%$ \\
São Lourenço & $4 \%$ & $4 \%$ \\
Tapes & $12 \%$ & $11 \%$ \\
Tavares & $4 \%$ & $6 \%$ \\
Turuçu & $4 \%$ & $0 \%$ \\
Viamão & $7 \%$ & $1 \%$ \\
\multicolumn{1}{c}{ TOTAL } & $\mathbf{1 0 0 \%}$ & $\mathbf{1 0 0 \%}$
\end{tabular}

Fonte: Autor.

Destaque para os municípios de Mostardas e São José do Norte, possui 29\%, da área irregular da APP da Lagoa dos patos individualmente, sendo que ambos representam $58 \%$ das ocupações irregulares no entorno da Lagoa, devido principalmente pelas atividades de pecuária e rizicultura que se mostram consolidadas há anos na região. Outro destaque dá-se aos municípios de Palmares do Sul, Pelotas e Turuçu, que não registram ocupações irregulares no entorno da Lagoa, na fração de APP em seus territórios.

\subsection{Análise econômica das áreas}

\subsubsection{Rizicultura}

A topografia e características do solo, em concomitância com a oferta hídrica da região, propicia um ambiente privilegiado para o cultivo do arroz. A atividade se mostra consolidada há anos no litoral norte rio-grandense e segundo a Associação dos Produtores de Arroz do Litoral Norte Gaúcho - APROARROZ, os grãos de arroz formados neste ambiente apresentam melhor aparência devido à disposição das moléculas de amido ocorrer de forma mais uniforme durante o período de enchimento dos grãos. Como consequência, propicia-se o surgimento de um grão mais duro, transparente, com maior vitricidade quando polido (APROARROZ, 2012).

Os resultados das análises apontaram uma área total de 925,03 hectares de cultivo de arroz situados na APP da Lagoa dos Patos. A produção do arroz, kg/ha, atinge cerca de $6.200 \mathrm{~kg} / \mathrm{ha}$ (IRGA, 2011) o que resulta numa produção anual estimada de 5.735,19 toneladas. Segundo informações atuais, provenientes do site AGROLINK, 
o preço da saca do arroz $(50 \mathrm{~kg})$ na região está cerca de $\mathrm{R} \$ 35,00$. Gerando um faturamento bruto anual de $\mathrm{R}$ \$4.014.630,20. Segundo informações do IRGA, os custos com taxas (CDO, FUNRURAL, LIC. AMBIENTAL) pagos pelos produtores de arroz, chegam a R \$ 135/ha, o que significa uma arrecadação anual de aproximadamente R \$ $124.879,05$ em impostos.

\subsubsection{Silvicultura}

A atividade silvicultura da região teve início em meados da década de 70 devido ao grande apoio governamental, mediante incentivos fiscais cujo objetivo era a formação de base florestal que posteriormente viria a viabilizar a instalação de alguns empreendimentos consumidores de matéria prima florestal no estado. O litoral norte riograndense caracteriza-se pela presença de inúmeros maciços florestais, principalmente da espécie Pinus elliotti, que fornecem madeira para construção civil de consumo local e para beneficiamento de madeira serrada para exportação. Destaca-se também a atividade de Resinagem bastante presente na região, que tem por objetivo a extração da goma resina do Pinus elliotti para fornecimento às fábricas de breu e terebintina do estado. A silvicultura foi estabelecida nas piores áreas do litoral, onde as atividades de pecuária e rizicultura não puderam se desenvolver pela baixa qualidade do solo que impedia uma boa produção de pastagem ou o correto desenvolvimento do arroz. Os resultados das análises apontam que a área total destinada à silvicultura, presente na APP da Lagoa, perfaz um total de 630,41 hectares, sendo 273,24 hectares de eucalipto e 357,17 hectares de pinus. Segundo o Anuário da Associação Brasileira de Produtores de Florestas Plantadas - ABRAF, base 2011, o incremento médio anual (IMA) de uma floresta de eucalipto é de 40,10 m³/ha/ano, ou seja, a floresta é capaz de crescer/produzir $40,10 \mathrm{~m}^{3}$ de madeira bruta por hectare a cada ano. Sendo assim a produção anual de eucalipto na APP da lagoa dos patos é de 10.956,92 $\mathrm{m}^{3}$. Segundo informações de produtores de eucalipto da região, o preço do $\mathrm{m}^{3}$ de madeira em pé para o eucalipto é de $\mathrm{R} \$ 60 / \mathrm{m}^{3}$, o que possibilita uma produção no valor de $\mathrm{R} \$ 657.415,44$ pelo incremento anual das florestas de eucalipto. Com relação às florestas de pinus, em consulta a

\footnotetext{
5 Fonte: Empresa Flosul, produtora de eucalipto da região. Fone: 051 3681-0100. Site: http://www.flosul.com.br
} 
produtores da região ${ }^{6}$, constatamos que o incremento médio anual para as florestas é de $22 / \mathrm{m}^{3} / \mathrm{ha}$, o que resulta numa possível produção de $7.857,74 \mathrm{~m}^{3}$ de madeira de pinus somente na APP da lagoa a cada ano. Considerando o preço da floresta em pé informado de $\mathrm{R} \$ 39,00 / \mathrm{m}^{3}$, obtemos o valor de $\mathrm{R} \$ 306.451,86$ pelo incremento anual das florestas de pinus. Cabe ressalvar que, consoante o Anuário da Associação Brasileira de Produtores de Florestas Plantadas - ABRAF, base 2011, o Incremento médio anual para as florestas de pinus brasileiras é de $35,9 \mathrm{~m}^{2} / \mathrm{ha}$, porém como a região litorânea do RS caracteriza-se por formações vegetais sob influência direta do mar, distribuída por terrenos arenosos do quaternário recente, geralmente com algum teor salino, sujeitos à intensa radiação solar e acentuada ação eólica (LEITE \& KLEIN, 1990), adotar-se-á como oficial o IMA informado pelos silvicultores da região, visto que pelas características edafoclimáticas o crescimento da floresta é inferior às demais regiões do país.

Através da consulta às empresas responsáveis por grande parte desta atividade no litoral, a arrecadação tributária para a atividade silvícola, existente na Área de Preservação Permanente da Lagoa dos Patos, é representada por 0,65\% (PIS), 3\% (COFINS) e 2,1\% (FUNRURAL) perfazendo um total de 5,67\% de impostos incidentes para tal atividade, o que significa um montante de $\mathrm{R} \$ 54.651,28$ recolhidos anualmente aos cofres públicos.

\subsubsection{Pecuária}

A criação de gado bovino no Rio Grande do Sul se fez presente antes mesmo de ser território brasileiro, pelo Tratado de Tordesilhas a região do Estado pertencia à Espanha e os padres jesuítas espanhóis foram os primeiros europeus a chegar, construir edificações, plantar e criar animais. (REICHERT et al, 2010).

Segundo a Associação Brasileira das Indústrias Exportadoras de Carnes-ABIEC, o Brasil é o quinto maior país do mundo em território, com 8,5 milhões de $\mathrm{km}^{2}$ de

\footnotetext{
${ }^{6}$ Empresa Florestal Mostardas com sede em Mostardas/e Tavares/RS. Fone: 0543462 5600, Site: http://www.madem.com.br e Empresa Habitasul Florestal com sede nos Municípios de Balneário Pinhal, Cidreira, Mostardas, Tavares e São José do Norte/RS. Fone: 051 3682-0102, Site: http://www.habitasul.com.br
} 
extensão, com cerca de $20 \%$ da sua área (174 milhões de hectares) ocupada por pastagens. (ABIEC, 2011).

Segundo a Embrapa Gado de Corte, a atividade apresenta índices zootécnicos muito baixos há décadas, com lotação das pastagens em torno de 0,5 cabeças/ha/ano, quanto ao desempenho animal a média do ganho de peso vivo, está na faixa de 100 $\mathrm{kg} / \mathrm{ha} /$ ano. Considerando este incremento médio anual, chegamos a uma estimativa de produção total anual de $68.888,00 \mathrm{~kg}$ de boi vivo para a atividade pecuária praticada na APP da Lagoa dos Patos. Com o preço do boi gordo de $\mathrm{R} \$ 3,50 / \mathrm{kg}$ (RURAL BR), chegamos a uma possível receita anual de $\mathrm{R} \$ 241.108,00$, que resulta numa tributação de $\mathrm{R} \$$ 5.063,268, referente a 2,1\% de incidência de FUNRURAL, (informação repassada pelo Presidente do Sindicato Rural de Palmares do Sul).

\subsubsection{Demonstrativo Geral}

A Tabela 4 apresenta a compilação de informações financeiras, resultado das análises e estimativas descritas acima.

Tabela 4 - Percentual das áreas regulares e irregulares por município

\begin{tabular}{ccc|}
\hline Atividade & $\begin{array}{c}\text { Faturamento } \\
\text { Anual }\end{array}$ & $\begin{array}{c}\text { Geração de } \\
\text { Impostos }\end{array}$ \\
\hline Rizicultura & $\mathrm{R} \$ 4.014 .630,20$ & $\mathrm{R} \$ 124.879,05$ \\
Silvicultura & $\mathrm{R} \$ 963.867,30$ & $\mathrm{R} \$ 54.651,28$ \\
Pecuária & $\mathrm{R} \$ 241.108,00$ & $\mathrm{R} \$ 5.063,27$ \\
TOTAL & $\mathbf{R} \$ \mathbf{5 . 2 1 9 . 6 0 5 , 5 0}$ & $\mathbf{R} \$ \mathbf{1 8 4 . 5 9 3 , 5 9}$ \\
\hline \hline
\end{tabular}

Fonte: Autor

\subsection{Pagamento por Serviços Ambientais - PSA}

A atividade antrópica existente na área em estudo, comprovadamente possui importância econômica para os produtores rurais ali instalados. $\mathrm{O}$ pagamento por serviços ambientais é um mecanismo que possibilitaria evitar o agravamento da ocupação já existente, mediante apoio financeiro, pelo governo, às comunidades e proprietários rurais que preservarem a vegetação nativa situada em áreas de preservação permanente. (BERNARDES et al, 2010) 
Programas que utilizam de PSA são considerados pela FAO (2004) mecanismos promissores para o financiamento da proteção e restauração ambiental, assim como forma de complementar e reforçar as regulações existentes, promovendo a conservação e recuperação ambiental. (BERNARDES et al, 2010)

O ICMS Ecológico é uma das formas de pagamento por serviços ambientais já praticadas no Brasil, criado através do artigo 158 da Constituição Federal, trata-se de um mecanismo fiscal que não mexe no bolso do contribuinte, pois diz respeito ao repasse obrigatório de parte dos valores do Imposto sobre Circulação de Mercadorias e Serviços - ICMS recolhidos pelos estados, o ICMS Ecológico passa a ser um dos critérios para o repasse desses valores e premia os municípios que possuem, por exemplo, Unidades de Conservação e áreas de mananciais. Em outras palavras, aquele município que incentivar os proprietários rurais a preservarem suas florestas e conservarem a biodiversidade local, ganha uma pontuação maior nos critérios de repasse e recebe recursos financeiros a título de compensação pelas áreas destinadas à preservação, e ao mesmo tempo, um incentivo para a manutenção e criação de novas áreas para a conservação da biodiversidade. Nesse sentido, o ICMS Ecológico é uma forma de Pagamento por Serviços Ambientais pela conservação de biodiversidade. (ICM-E, 2013)

\section{CONCLUSÕES}

As técnicas de geoprocessamento mostraram-se eficazes no diagnóstico preliminar do estado de ocupação da área de preservação permanente da Lagoa dos Patos, através da utilização de dados geográficos disponibilizados gratuitamente por entidades governamentais. $\mathrm{O}$ trabalho apontou uma irregularidade em $26 \%$ da área total APP da referida Lagoa, mas através do contato com produtores da região e entidades representantes de classes, constatou-se que tal irregularidade é representada por atividades agrossilvipastoris rentáveis já consolidadas há anos no litoral.

Em contrapartida, surpreende que $74 \%$ da área de APP de uma das maiores lagoas do mundo, que abrange o território de inúmeros municípios em um Estado que possui na agricultura sua maior fonte de renda, esteja devidamente preservada. 
A possível rentabilidade e tributação gerada por essas atividades rurais, não justifica a sua permanência perpétua na área de preservação da Lagoa. Faz-se necessária uma aproximação governamental junto aos produtores rurais, buscando a recuperação das áreas de preservação ocupadas de forma gradativa, estabelecendo prazos e garantindo incentivos àqueles que cumprirem as metas de desocupação.

O pagamento por serviços ambientais pode ser a solução de equilíbrio entre a recuperação/conservação ambiental e geração de renda para pequenos e médios produtores da região.

Por fim, o presente trabalho apontou a necessidade de uma investigação mais aprofundada, com relação às atividades antrópicas desenvolvidas na área de preservação permanente da Lagoa dos Patos. Como oportunidade de aproximação junto aos produtores rurais, de forma a promover a conscientização sobre a importância da proteção dos mananciais em consonância com o desenvolvimento sustentável das atividades rurais potenciais, praticadas na região.

\section{REFERENCIAS}

LEITE, P.F. \& KLEIN, R.M. 1990. Vegetação. In Geografia do Brasil: Região Sul. Instituto Brasileiro de Geografia e Estatística, Rio de Janeiro, v. 2;

ABRAF. Anuário estatístico da ABRAF 2012, ano base 2011/ABRAF. - Brasília. Brasil: 2012;

ASMUS, M.L. A Planície Costeira e a Lagoa dos Patos. In: U. Seeliger, C. Odebrecht e J.P. Castello. Os Ecossistemas Costeiro e Marinho do Extremo Sul do Brasil. Rio Grande/RS: Editora Ecoscientia. 1998;

IRGA, Instituto Riograndense do Arroz. Custos de produção: Safra 2010/11. Disponível em <http://www3.irga.rs.gov.br/uploads/anexos/1293728428Custos_de_Producao.pdf> Acessado em 15/03/2013;

BRASIL. Lei federal n. 12.651, de 25 de maio de 2012. Institui o Novo Código Florestal Brasileiro. Diário Oficial da União, Brasília, DF, mai. 2012. Disponível em: <http://www.planalto.gov.br/ccivil_03/_Ato2011-2014/2012/Lei/L12651.htm>.

Acessado em: 03/03/2013;

PEREIRA, R. S.; Niencheski, L. F. H. \& Baumgarten, M. G. Z. Condição Ambiental da Lagoa dos Patos. $1^{\circ}$ Simpósio de Recursos Hídricos do Sul. Rio Grande do Sul. Brasil. 2005;

TYRREL, D. A. \& GEORGE, K. J. Finite Element Modelling of the Hydrodynamics and Water Quality of the Patos Lagoon System, Brazil. In: International Coastal Symposiun. Brasil. 2005; 
ESRI, Environmental Systems Research Institute. ArcGis 9.1(handbook). Redlands: Environmental Systems Research Institute, 1999. 4v;

APROARROZ. Associação dos Produtores de Arroz do Litoral Norte Gaúcho. Disponível em <http://www.aproarroz.com.br> Acessado em 05/05/2013;

REICHERT, H.; FILHO, P.J.M. \& SCHUMACHER, G. A Pecuária no Rio Grande do Sul: A Origem, a Evolução Recente dos Rebanhos e a Produção de Leite. Universidade Federal de Santa Maria. Rio Grande do Sul. Brasil. 2010;

MMA, Ministério do Meio Ambiente. Download de Dados Geográficos. Disponível em http://mapas.mma.gov.br/i3geo/datadownload.htm. Acessado em 05/03/2013;

IBGE, Instituto Brasileiro de Geografia e Estatística. Downloads Geociências. Disponível em <http://downloads.ibge.gov.br/downloads_geociencias.htm> Acessado em 05/03/2013;

ABIEC, Associação Brasileira das Indústrias Exportadoras de Carne. Disponível em http://www.abiec.com.br/ Acessado em 24/08/2013;

AGROLINK. Cotações. Disponível em http://www.agrolink.com.br/cotacoes/ Acessado em: 24/03/2013;

KOZERA, C; KUNIYOSHI, Y.S.; GALVÃO, F.; CURCIO, G.R. Composição Florística De Uma Formação Pioneira Com Influência Fluvial Em Balsa Nova, Pr, Brasil. 2008;

ICM-E, Site do ICM Ecológico. Disponível em: <http://www.icmsecologico.org.br/>. Acessado em: 26/08/2013;

MESQUITA, E.A; CRUZ, M.L. B \& PINHEIRO, L.R. Geoprocessamento Aplicado ao Mapeamento das Formas de Uso da Terra na Área de Preservação Permanente (APP) daLagoa do Uruaú - Beberibe/Ce. Brasil. 2012;

BERNARDES, C.B. \& JUNIOR, W.C.S. Pagamento por Serviços Ambientais: Experiências Brasileiras relacionadas à Água. V Encontro Nacional da Anppas 4 a 7 de outubro de 2010. Florianópolis/SC. Brasil. 2010;

COUTINHO, L.M. \& CECÍLIO, R.A. Delimitação e estudo de vulnerabilidade da Área de Preservação Permanente no entorno da Lagoa Guanandi, Itapemirim-ES. Anais XV Simpósio Brasileiro de Sensoriamento Remoto - SBSR, Curitiba, PR, Brasil, 30 de abril a 05 de maio de 2011, INPE p.5868;

GOUDINHO, V.M.; ALEXANDRE, M.S. \& CRUZ, M.L.B. Uso do Sensoriamento Remoto na identificação da pressão antrópica na Lagoa do Catú - Aquiraz / Ceará. Anais XIV Simpósio Brasileiro de Sensoriamento Remoto, Natal, Brasil, 25-30 abril 2009, INPE, p. 3859-3865.

BRASIL. Constituição (1988). Constituição da República Federativa do Brasil. Brasília, DF, Senado, 1988. Disponível em http://www.planalto.gov.br/ccivil_03/constituicao/constituicao.htm>. 